IGNACIO FALGUERAS

Universidad de Málaga

jifalgueras@uma.es

\title{
Del círculo mágico a Las edades del mundo. Algunos implícitos filosóficos
}

\section{From the Magic Circle to The Ages of the World. Some Philosophical Implications}

RESUMEN: Una vez conocidas las nociones de círculo mágico y de eones eternos, que fueron estudiadas en un trabajo precedente, y a fin de comprender mejor la propuesta filosófica de Schelling, se investigan aquí algunos problemas filosóficos implícitos en dichas nociones. Y se concluye que el propósito de enmendar, mediante cierto realismo, el logicismo de hegel -y el suyo propio precedente- no finaliza satisfactoriamente, por conservar los planteamientos idealistas básicos de su juventud.

PALABRAS CLAVE: SCHELLING; HEGEL; MAGIA; CÍRCULO; MOVIMIENTO ROTATORIO; ETERNIDAD; TIEMPO; EONES ETERNOS; REALISMO; IDEALISMO; VOLUNTAD; CONCIENCIA

\begin{abstract}
The notions of «the magic circle» and «eternal aeons» have been researched in a previous work to clarify Schelling's proposal. Now we can research some implicit philosophical problems inherent to these notions. It is concluded that understanding Hegel's logicism by a sort of realism - and his own precedent - is not a satisfactory idea. The problem is that it preserves his basic idealistic approaches since his youth.

KEY WORDS: SCHELLING; HEGEL; MAGIC; CIRCLE; ROTATION; ETERNITY; TIME; ETERNAL EONS; REALISM; IDEALISM; WILL; CONSCIOUSNESS
\end{abstract}




\section{INTRODUCCIÓN}

Zn una pUblicación AnTERIor, y como vanguardia de esta misma invesEtigación, estudié la evolución de las nociones de "círculo mágico» y de «eones eternos» en las obras de Schelling, nociones que fueron utilizadas por él para responder al planteamiento filosófico de Hegel $^{1}$. Con el fin de intentar comprender más a fondo el pensamiento de Schelling, voy a prestar atención, en este segundo tramo de la investigación, a ciertos problemas filosóficos implícitos en sus nociones de «círculo mágico» y de «eones eternos». La exposición de tales problemas será hecha en el siguiente orden: empezaré por la primera de ellas (II), considerando los que afectan al substantivo de esa expresión, a saber: «círculo» (II.1), seguiré por los relativos al adjetivo «mágico» (II.2); y examinaré, después, los problemas de la conjunción de ambos en la noción de movimiento rotatorio (II.3). A continuación, pasaré a considerar algunos problemas implícitos en la noción de «eones eternos» (III). Y, finalmente, para concluir propondré los implícitos ulteriores de su pensamiento (IV).

\section{Problemas IMPLí́CITOS EN LA NOCIÓN DE «CírCUlO MÁGICO»}

\section{II.1. EL «CÍRCULO»}

Según lo expuesto en la primera parte de este trabajo, Schelling asocia el círculo con lo que él considera ser el sujeto absoluto, o sea, con lo infinito. Y ése es, precisamente, el primero de los problemas a considerar, a saber, la noción de círculo infinito, pues si algo es claro es que el círculo, o la circunferencia, es finito: está acabado. Tanto es así que, para poder pensar un círculo infinito, es preciso imaginar que los puntos del círculo están en un movimiento inacabable, aunque, como es obvio, en tal caso lo infinito sería el movimiento inacabable, no el círculo. Si bien dejo para el subapartado tercero la consideración de algunos implícitos del movimiento rotatorio, quede claro ya desde ahora que, para pensar un círculo infinito, se han de igualar el movimiento circular y el círculo.

El movimiento circular, o rotatorio, se da en el mundo físico, pero no traza nunca un círculo o una circunferencia perfectos, sino sólo un movimiento en espiral. El lugar y el tiempo físicos varían interna e incesantemente, de manera que cualquier movimiento circular en el mundo físico acaba siempre en un lugar y momento temporal distintos de aquellos en los que comenzó, razón por la que no llegan nunca a cerrarse en círculo perfecto. El círculo, o sea, la coincidencia exacta del punto de partida y de llegada, sólo se da en el pensa-

[1] I. Falgueras, "Del círculo mágico a las edades del mundo. Un recorrido a través de las obras de Schelling", en Juan J. Padial, Alejandro Rojas (Hrsg.), Wahrheit und Freiheit in den philosophischen Systemen von Schelling und Hegel, Olms, Hildesheim, 2020. 
miento, y es palmariamente finito, pues tiene que quedar cerrado o acabado para que lo sea, cosa que no ocurre con los movimientos circulares físicos, los cuales pueden proseguir indefinidamente. Y, por otro lado, aunque Schelling lo pretende $^{2}$, nada tiene que ver la vida con el círculo, pues si bien es verdad que la vida es movimiento inmanente, o sea, con feed-back o retroactividad, dicha retroactividad orgánica es también un movimiento físico, $y$, por tanto, que tarda tiempo -aunque lo gane en relación con lo carente de vida -, por lo que no llega a formar un círculo verdadero, tan sólo un movimiento con término interno y en espiral creciente.

Otra cosa es que nosotros nos imaginemos la vida y el movimiento circular como círculos cerrados. La imagen del círculo tiene que ver con su trazado: centro, radio y periferia. Mas incluso esta imaginación, siendo intermedia entre los movimientos circulares físicos y el círculo pensado ${ }^{3}$, es también un movimiento intracerebral (formalizado), que distribuye según el antes y el después la información recibida sensiblemente de los procesos naturales y ordenada de acuerdo con una idea ${ }^{4}$. Por lo mismo, nunca existe una coincidencia exacta entre el punto de partida y el de llegada en el trazado -imaginado y efectivo, o meramente imaginado- de una circunferencia, si bien esa diferencia suele ser considerada como despreciable, pero sólo para la práctica y por quien ya sabe lo que es un círculo o una circunferencia perfectos ${ }^{5}$.

[2] „Jenes ursprüngliche, nothwendige und bleibende Leben steigt also wohl vom Untersten zum Höchsten auf, aber angekommen in diesem geht es unmittelbar auf den Anfang zurück, um von diesem wieder aufzusteigen; und hier erst gelangen wir zu dem vollkommenen Begriff jener ersten Natur (nachdem nun alle einzelnen Begriffe wieder entfernt werden müssen, die nur gesetzt werden mußten, um zu diesem vollkommenen Begriff zu gelangen), nämlich daß sie ein ewig in sich selbst kreisendes Leben ist, eine Art von Cirkel, da das Unterste immer in das Oberste, und das Oberste wieder in das Unterste läuft" (Die Weltalter. Bruchstück, F. W. J. Schellings Sämtliche Werke (SW), herausg. von K.F.A. Schelling, Cotta Verlag, Stuttgart, 1856-1861, VIII, 229).

[3] Es intermedia, porque siendo ella misma un movimiento (motus factus a sensu secundum actum, Aristóteles, Perì psichés III, 429 a 1-2; Tomás de Aquino, Contra gentiles II, c.73, n.11), es un movimiento dirigido por una idea (atemporal e inmóvil) que intensifica su formalización. Esto permite ordenar los procesos físicos según una idea, pero también trocear en fases la unidad de la idea, introduciéndola en el tiempo, que es el que la hace efectiva.

[4] En general, la imaginación reelabora formalmente la información sensorial recopilada por el sensorio común, abreviándola (esquema). Pero la imaginación humana es sometida por el entendimiento y la voluntad a una finalidad no natural, a saber, a la ordenación temporal de una idea humana.

[5] Igualo circunferencia y círculo, porque en realidad la diferencia entre ellos y con la esfera, no es más que una diferencia de dimensiones: circunferencia, una dimensión; círculo, dos dimensiones; esfera, tres dimensiones. Pero las dimensiones son espaciales, es decir, físico-imaginativas, mientras que la noción de circunferencia es puramente mental. O lo que es igual: no 
En cambio, pensar no es movimiento alguno, y, por eso, cabe objetivar el círculo sin movimiento y sin tiempo, o sea, de una sola vez. En realidad, la circunferencia es el objeto único de la conciencia, con la que coincide perfecta y atemporalmente ${ }^{6}$. Schelling podría haberse dado cuenta de esto, cuando descubrió que incluso el punto es un círculo ${ }^{7}$, y también cuando afirmó que la magnitud o el tamaño no forma parte de la esencia del círculo ${ }^{8}$, de manera que todos los círculos son iguales, es decir: no hay más que un círculo. Ambas observaciones llevan a distinguir netamente entre el círculo pensado y el círculo imaginado, pues entre las circunferencias construidas o meramente imaginadas por el hombre existen diferencias, en la medida en que el tamaño depende del radio, y su construcción depende de un punto central distinto de ella misma; mientras que el círculo pensado es uno solo y el mismo en todos los casos -incluido el punto, como círculo de radio 0-, con total independencia del espacio y del tiempo, porque está presente todo él a la vez ante la conciencia, lo cual está vinculado, precisamente, con su finitud. Sin embargo, la pretensión de pensar un círculo infinito obliga a Schelling, según se ha visto, a imaginarlo como un movimiento rotatorio perfecto, aunque dotado de comienzo, medio y fin.

En suma, para poder hablar de un círculo infinito es preciso confundir lo pensado (círculo) con la realidad física (movimiento circular), utilizando como medio la imaginación (trazado del círculo en el espacio y el tiempo). Que Schelling lo haga así queda confirmado por su descripción de la vida eterna como un movimiento rotatorio infinito, en cuyo «trazado» (imaginario) tiene que distinguir, primero, tres momentos, para decir a continuación que, por ser un movimiento infinito (pensado), esos tres momentos (principio, medio y fin) no pueden separarse, es decir, no pueden ser distinguidos realmente en ella ${ }^{9}$.

\section{II.2. «MÁGICO»}

Paso, ahora, a considerar el adjetivo «mágico», que es el segundo término de la expresión «círculo mágico». La función de la magia en el último Schelling es

existen diferencias nocionales entre esas tres figuras, de las que la circunferencia es, imaginativamente, la más sencilla.

[6] L. Polo, Curso de Teoría del Conocimiento, vol. II, lecciones X y XI, en Obras Completas de Leonardo Polo (OC), Eunsa, Pamplona, 2016, V, 179-219; cfr. en especial, 196.

[7] System dergesamten Philosophie (1804), SW VI, 167. Cfr. Initia Philosophiae Universae, H. Bouvier \& Co. Verlag, Bonn, 80; Philosophische Einleitung in die Philosophie der Mythologie, SW XI, 318.

[8] Grundlegung der positiven Philosophie, H. Fuhrmans, Bottega d'Erasmo, Torino, $1972,342$.

[9] Weltalter. Bruchstück, SW VIII, 229-230; Philosophie der Offenbarung, SW XIII, 258259. 
la de servir de puente entre la voluntad y el círculo, que de suyo está vinculado con la conciencia, no con la voluntad. Me detengo un momento en este punto.

Conviene notar que el carácter circular, tanto en Fichte ${ }^{10}$ como en Hegel $^{11}$ está asociado expresamente con la conciencia, cosa por lo demás justificada, según lo expuesto más arriba, y coherente, puesto que ellos intentan alcanzar un sistema del saber que abarque todo lo sabido y esté basado en la conciencia ${ }^{12}$. Debe tenerse en cuenta, por otro lado, que esa misma asociación aparece ya en el pensamiento antiguo, cuando se atribuye inteligencia a los astros por razón de su movimiento circular ${ }^{13}$. Si buscamos las razones con las que justifican la asociación entre el círculo y la conciencia, encontramos como las más radicales: que el movimiento circular es imitación de la eternidad ${ }^{14}$, que el movimiento circular es la medida de los demás movimientos ${ }^{15}$, y que el círculo es la imagen de la perfección, perfección que estriba en su acabamiento, pues el trazado de la circunferencia acaba donde empieza y empieza donde acaba, de manera que nada le falta ni le sobra, está toda entera de una vez ${ }^{16}$. Por eso, si uno quiere pensar un movimiento perfecto, entonces lo habrá de pensar como circular, y asociado en alguna medida a una conciencia o presencia mental.

Vuelvo ya a considerar la magia. A diferencia del círculo, la magia se relaciona de modo natural con la voluntad, porque -como indicaba Schellingella es concebida por nosotros como un poder directo de la voluntad sobre la

[10] „Soll die nothwendige Handlungsart der Intelligenz an sich in die Form des Bewusstseyns aufgenommen werden, so müsste sie schon als solche bekannt seyn, sie müsste mithin in diese Form schon aufgenommen seyn; und wir wären in einem Cirkel eingeschlossen" (Über den Begriff der Wissenschaftslehre, J.G. Fichtes Sämtliche Werke, herausg. von I.H. Fichte, Veit \& Comp. 1845/1846, I, 72).

[11] „So wird das Bewusstsein auf seinem Wege von der Unmittelbarkeit aus, mit der es anfängt, zum absoluten Wissen als seiner innersten Wahrheit zurückgeführt" (Wissenschaft der Logik, I, HW 5, 70)

[12] Según Kant, maestro de ambos, no podemos pensar un círculo sin describirlo imaginativamente en el espacio (Kritik der reinen Vernunft, B154-155 y nota), pero cuando lo pensamos no hacemos más que postularlo, es decir, expresar el procedimiento (sintético) por el que producimos el objeto y su concepto en la conciencia (B287).

[13] Aristóteles, Metaph. XII, 1073 a23 ss.; Plotino, Enéada II, 2, 1.

[14] Platón, Timeo, 37c-38d.

[15] Physica, libro 4, c. 14, 223b18-20. Téngase en cuenta que el tiempo es la medida o número del movimiento según el antes y el después, y lo es mediante el ahora (nun), puesto por el alma (O.c. 4, 11, 219a26-b2). Si el movimiento circular es medida de los demás movimientos, entonces el alma ha de tener también alguna relación con el movimiento circular.

[16] "Circulus dicitur esse figura perfecta, quia habet idem principium et finem" (Aristóteles, Phys. VIII, 8, 264b27-28; citado por Tomás de Aquino, Summa Theologiae (ST), I-II, 3, 7 obj.2), cfr. Contra gentiles II, 46, n.2). Por ser perfecto, el movimiento circular no admite tener opuesto (Tomás de Aquino, In II Sent., d. 17 q. 3 a. 1 s.c. 2; ST I, 66, 2 c). 
naturaleza sin mediación de operación corporal alguna ${ }^{17}$. Pero si la magia se asocia de modo natural con la voluntad, la voluntad, en cambio, no necesariamente se ha de asociar con la magia. ¿Por qué no asocia Schelling, como es habitual, la voluntad divina con la omnipotencia creadora? Porque la magia divina, según él, no se refiere directamente a la creación, sino al estado de la voluntad divina previo, o puramente potencial ${ }^{18}$. La omnipotencia es, para él, el fuego divino que arrasa lo concreto, la ira divina que suprime la naturaleza, mientras que la magia es la atracción inconsciente que la voluntad durmiente ejerce sobre las potencias aún no separadas: la omnipotencia implica la conciencia (voluntad despierta); la magia no, pues -dice Schelling- no es posible una conciencia eterna ${ }^{19}$. ¿Qué es, entonces, lo que busca Schelling al asociar magia y voluntad en Dios?

Dado que, según Schelling, la magia que conocemos de modo natural los hombres no es precisamente perfecta, sino la falsa magia, -el efecto de la caída, o del intento de ser como dioses dominando las potencias-, para poder pensar una magia perfecta, lo que se le ocurre es asociarla, y junto con ella a la voluntad, con la circularidad, que, de acuerdo con lo expuesto antes, es el objeto perfecto. En efecto, concebida como una potencialidad ${ }^{20}$ auto-activa perfectamente circular, o sea, en cuyo movimiento no se distingue el principio, el medio y el final, la voluntad hace suyo lo característico de la circularidad, aunque de modo inconsciente, a diferencia de cuanto sostienen todos los filósofos precedentes: la voluntad durmiente sería una actividad que no tiene un comienzo ni -de suyo- un término final (rotación) determinados, y que, por

[17] „1) daß der Mensch in gewissen Fällen oder unter gewissen Bedingungen eines unmittelbaren Einflusses auf die Natur durch seinen bloßen Willen, ohne körperliche Mittel, fähig sey - Glaube an Magie so alt, wie es scheint, als die Menschheit selbst“ (Ph. d. Offenbarung, SW XIII, 362).

[18] „- gerade darum, weil es in seiner Ueberwundenheit Grund der Natur, ist es in seiner unbeschränkten Allmacht, in seinem ausschliesslichen Seyn das Aufhebende aller Natur, es ist, wie wir sagten, jenes Vordere, Vorausgehende, jenes Angesicht Gottes, das kein Mensch sehen kann und leben, das alles Concrete wie mit Feuer zerstören würde. Wie es im ursprünglichen Bewusstseyn war, ist es rein geistig und zugleich das bleibende Princip, der Anziehungspunkt aller andern Potenzen, über die es eine gleichsam magische Gewalt ausübt, magisch, weil es sich dabei als ein ruhender Wille (reine Potenz) verhält; tritt es nun aus seinem An-sich hervor, so stösst es diese höheren Potenzen vielmehr zurück und schliesst sie aus, statt sie anzuziehen" ( $P h$ d. Offenbarung, SW XIII, 386).

[19] Weltalter. Bruchstück, SW VIII, 262.

[20] La magia no es actual, sino potencial: "Er [der Mensch] hat über sie [potenzen] Macht nur, wenn er sich nicht bewegt (keine aktuelle, sondern nur eine magische Macht)" (Ph. d. Offenbarung, SW XIII, 349). Aunque el texto se refiere al hombre, indirectamente indica que el poder mágico de la voluntad durmiente no es actual. Las palabras entre corchetes han sido intercaladas por el autor de este artículo. 
estar en continuo movimiento (circular), sería infinita en todos sus momentos. Ahora bien, la magia se caracteriza por la ocultación de sus procedimientos, y así la voluntad durmiente es mágica por ser oculta incluso para sí misma, ya que ejerce la circularidad sin saberlo. Y esto debería ser especialmente verdadero cuando se despierta a sí misma, pues no se ve de ningún modo cómo pueda hacerlo, y en rigor ni siquiera ella misma podría saberlo. De ahí que «magia eterna» equivalga, para Schelling, a «misterio» ${ }^{21}$, pero un misterio en un sentido inaceptable, pues lo es incluso para Dios, y, por tanto, que equivale a la irracionalidad. La decisión es inmemorial (unvordenklich) no sólo porque está tomada antes de todo tiempo, sino también antes de todo plan o conocimiento. Por consiguiente, lo único que aporta la noción de magia es la indicación de un poder oculto e irracional que precede a la conciencia, pero que -cuando ésta sobreviene- la fascina, haciéndole pasar por alto el sinsentido de un acto de la voluntad concebido como circular, pues si algo es claro es que la voluntad tiende, pero no hacia sí misma, sino hacia fines que ella desea, y que, en esa medida, se sitúan fuera de ella.

Es un error atribuir la circularidad a la voluntad, porque la voluntad como deseo no es perfecta, mientras que el círculo sí lo es ${ }^{22}$. La voluntad puede ser curva, pero no circular ${ }^{23}$. Cuando es durmiente, no es perfecta, porque es

[21] „So nah liegt jedem Menschen der Ungrund der Ewigkeit, vor dem er sich entsetzt, wenn er ihm vor's Bewusstseyn gebracht wird. / Vor der aus jener Tiefe kommenden Handlung ist kein Grund anzugeben; sie ist so, weil sie so ist, sie ist schlechthin und in so fern nothwendig. Vor dieser grundlosen, durch sich nothwendigen, Freyheit scheuen sich die Meisten, wie sie sich vor der Magie, vor allem Unbegreiflichen und besonders vor der Geisterwelt scheuen. ... Dieses Handeln aus dem Ungrund ist der geheime Talisman, die dunkle erschreckende Gewalt, wodurch bisweilen der Wille eines einzigen Menschen die Welt vor sich zu beugen vermag. Vielleicht ist das Geheimniss ein Glück, das darauf ruht" (Die Weltalter, Fragmente, In den Urfassungen von 1811 und 1813. Schellings Werke. Münchner Jubilaeumsdruck. Nachlaßband. Hrsg. von Manfred Schröter. München, ${ }^{2}$ 1979, 93). "Kein Wille aber offenbart sich anders als durch die That, durch die Ausführung. ... Solange ein Wille nur Wille und nicht in That übergegangen ist, so lange ist er Geheimniss, aber die That ist seine Manifestation, durch diese hört er also auf Geheimniss zu seyn und kann nicht bloss erkannt, sondern nun sogar durch Nachdenken und Combination begriffen werden“ (Ph. d. Offenbarung, SW XIV, 11).

[22] El hecho de que lo ponga en la vida divina es un indicio de que, en algún sentido, así lo piensa Schelling.

[23] Desde antiguo se suele decir que la voluntad es curva (cfr. L. Polo, Antropología Trascendental II, OC XV, 367; y L. Polo, Nietzsche, OC XVII, Eunsa, Pamplona, 2018, 96 en notas). Pero lo curvo no es necesariamente circular. La circunferencia es la curva perfecta, pues se cierra sobre sí misma, se da de una sola vez, y no admite incremento ni decremento. La voluntad, por el contrario, admite aumento y disminución, es decir, perfeccionamiento, porque su acto tiende hacia fuera de ella y no es puesto de una sola vez. La curvatura, o efecto interno del querer, es compatible con la intencionalidad o tendencia hacia otro; la circularidad no, precisamente porque es cerrada. 
potencia pura pasiva. Cuando está en estado de soñante, tampoco es perfecta, pues el sueño que correspondería a la voluntad sería el deseo inconsciente, pero sólo se desea lo que no se tiene, mientras que el círculo o la circunferencia es perfecta porque no le falta ni le sobra nada. Naturalmente, cabría decir que esa perfección circular se obtiene en el tercer estado, en el de despierta: el acto de la voluntad es el querer. Pero, aparte de que el querer es creciente, es decir, no acabado ni perfecto, la razón mencionada no la podría aducir Schelling, ya que justamente es en el tercer estado de la voluntad en el que, según él, se pierde la circularidad y se convierte en rectilinearidad: la conversión del movimiento circular en rectilíneo coincide exactamente con el tránsito de la voluntad que no llega a querer (indiferente y deseante) a la voluntad que quiere (despierta).

La voluntad que describe Schelling es indudablemente la voluntad humana, que sí es potencia pasiva, que ha de ser despertada, y que, una vez despierta, quiere, o pasa al acto $^{24}$. Pero pensar que esa misma voluntad puede ser atribuida -tal cual, y en su abierta imperfección- a Dios es, sencillamente, un despropósito inadmisible que destruye la dignidad y la simplicidad divinas. No es de extrañar que Schelling haya de acudir a la magia para intentar camuflar la innegable imperfección de una voluntad que duerme y se despierta. Apelar a la fascinación de lo mágico, que de suyo no explica nada, es una manera de distraer la atención sobre lo inadmisible: introducir en Dios la imperfección y la complejidad ${ }^{25}$.

\section{II.3. El MOVIMIENTO ROTATORIO, IMPLÍ́CITOS Y PROBLEMAS}

Como indiqué al principio de este examen, Schelling interpreta la vida divina como un movimiento infinito en forma de rotación ${ }^{26}$. La razón que tiene para introducir el movimiento rotatorio en Dios es la de neutralizar a Hegel, porque dicho movimiento es claramente físico, o sea, perteneciente a la filoso-

[24] La descripción de la voluntad en tres fases es un acierto de Schelling (cfr. I. Falgueras, "Introducción general a las obras completas de L. Polo", en Obras Completas de Leonardo Polo, Eunsa, Pamplona, 2015, I, 74), aunque lo no sea completo, y esté situado fuera de lugar: en Dios, $y$ no en el hombre.

[25] Para intentar validar su aplicación a Dios, no cabría alegar, contra lo anterior, que Schelling se está refiriendo a una voluntad infinita, pues la infinitud no hace variar la «cualidad» de lo atribuido: una voluntad que duerme, se despierta, y quiere, no será nunca una voluntad simple, por muy infinita que se la pretenda. Ése ha sido el error de Espinosa: creer que, si el $o b$ jeto es infinito, entonces es Dios. Un objeto infinito sería todavía un objeto, nunca una persona, mucho menos Dios. Schelling, que recrimina al Dios de Espinosa el ser ciego (Zur Geschichte der neuren Philosophie, SW X, 35), no elimina su ceguera, sólo la recluye en la vida divina originaria.

[26] Weltalter. Bruchstück, SW VIII, 261. Mas no por ser infinito dejaría este movimiento de ser movimiento, es decir, de ser complejo, lo que es totalmente inadecuado para la simplicidad exigida por el ser de Dios. 
fía de la naturaleza, y así puede reemplazar con un movimiento efectivo y real el movimiento meramente lógico del concepto, que constituye la vida divina en Hegel. Hablar de movimiento del concepto es, sin duda, un uso traslaticio de la palabra «movimiento ${ }^{27}$, porque si algo está quieto y no se mueve física o efectivamente, eso es lo pensado -y el concepto es pensado-. Pero, puesto que el concepto hegeliano pretende moverse en círculos (pensados), Schelling quiere oponerle una circularidad efectiva. Sin embargo, también Schelling hace un uso traslaticio de la noción de movimiento circular, puesto que atribuye dicho movimiento a la voluntad, que tampoco es física. Por tanto, los usos de las nociones de movimiento circular en ambos casos deberían ser entendidos como metafóricos; de lo cual se infiere, indirectamente, que lo que en verdad contrapone Schelling a Hegel es el establecimiento de la voluntad como principio de la vida divina frente al concepto lógico. En la Wissenschaft der Logik de Hegel, el concepto se hace libre a sí mismo, convirtiéndose al final en voluntad que decide alienarse. En cambio, Schelling pone la voluntad al principio, en medio y al final, y pretende subrayar con la metáfora del movimiento rotatorio el carácter clausurante o individuante ${ }^{28}$ de su poder inicial, que considera afín a la causalidad de lo físico.

¿Tiene razón Hegel? No, porque el concepto no se mueve, ni siquiera tiene actividad propia, y menos aún piensa, pues - contra la idea que desde Espinosa ${ }^{29}$ ha cundido en la filosofía- lo pensado no piensa ${ }^{30}$. A ese respecto, Schelling le dice a Hegel: lo que se mueve es el pensamiento del que piensa, no lo pensado ${ }^{31}$, acertando de este modo a detectar el carácter muerto o abstracto del objeto. Sin embargo, él, en vez de separar la noción de movimiento circular (que es física) respecto de la actividad del espíritu, los identifica a ambos en la voluntad pura. ¿Tiene razón Schelling? No, cuando refiere el movimiento rotatorio a la voluntad; sí la tiene, al negar el movimiento circular del concepto, aunque lo hace de modo insuficiente, puesto que admite que también el pensar es movimiento, sólo que rectilíneo. Y ambos se equivocan al poner el movimiento en

[27] El movimiento del que habla Hegel es el dialéctico o especulativo (Phänomenologie des Geistes, G. W. F. Hegel Werke (HW) in zwanzig Bänden, Suhrkamp V., Freiburg a. M., 1982, B. 3, 61), o sea, el movimiento del espíritu (Fragment zur Philosophie des Geistes, HW, B. 11, 527-528, y 531). No es, pues, lo que designa la palabra movimiento, que se refiere a lo físico.

[28] Según Schelling, el movimiento rotatorio es el principio de la individuación o separación del individuo singular respecto de lo general, cfr. Initia $P h . U ., 165$.

[29] "Primum, quod actuale Mentis humanae esse constituit, nihil aliud est, quam idea rei alicujus singularis actu existentis" (Ethica, II, Prop. XI, en Spinoza Opera herausg. von C. Gebhardt, C. Winters Universitaetsbuchhandlung, Heidelberg, II, 94.

[30] Cfr. L. Polo, Curso de Teoría del Conocimiento, tomo II, OC, V, 181; y tomo IV, OC VII, 92.

[31] Zur Geschichte, SW X, 131-132. 
Dios. Lo cual, en el caso de Schelling, provoca unas incongruencias radicales en sus propuestas, que es conveniente examinar.

Paso, pues, a considerar las incongruencias derivadas de poner el movimiento rotatorio puro en Dios. Por un lado, la rotación divina es denominada directamente movimiento, pero, a la vez, es considerada por él como inmovilidad $^{32}$, e igualada con el motor inmóvil aristotélico ${ }^{33}$. ¿Qué es, entonces: movimiento o inmovilidad? Schelling parece obviar el problema acudiendo a un subterfugio, a saber, a distinguir entre lo interior y lo exterior a ese movimiento ${ }^{34}$. Pero esa distinción alude a algo que todavía no habría ocurrido -lo exterior-, y que, por tanto, no debería ser tenido en cuenta para entender este otro movimiento, dado que cuando estaba vigente el movimiento rotatorio puro no existía ninguna otra cosa exterior a él. En Aristóteles, lo propio de Dios no es moverse circularmente -cosa que pertenece a los astros-, es ser inmóvil, de manera que el recurso a Aristóteles tampoco resuelve la contradicción de llamar movimiento a la inmovilidad, ni la incongruencia de poner ambas cosas en Dios.

$\mathrm{La}$ argucia ulterior de Schelling en este punto parece ser la de considerar que el movimiento rotatorio (el poder-ser) es la pura movilidad, o sea, el equivalente al (puro) móvil ${ }^{35}$, una condición de posibilidad del movimiento efectivo -que, según él, sería el rectilíneo-. Es verdad que el móvil no es el movimiento, sino lo

[32] „Freiheit oder der Wille, sofern er nicht wirklich will, ist der bejahende Begriff der unbedingten Ewigkeit, die wir uns nur ausser aller Zeit, nur als die ewige Unbeweglichkeit vorstellen können“. (Weltalter. Bruchstück, SW VIII, 235). "Sie (die lautere Gottheit) ist diess ohne Wandel oder Wechsel in ihr selbst, nicht weil ihre Lauterkeit aufgehoben, sondern eben weil sie diese höchste Lauterkeit und Freiheit ist. Sie ist es ohne alle Bewegung, in der tiefsten Ruhe, unmittelbar durch sich selbst (Weltalter. Bruchstück, SW VIII, 299). Cfr. Initia Ph. U., 115: "Denn die Ewigkeit ist an sich nichts anderes als eine lautere Stille, eine Unbeweglichkeit"; $P h$. d. Offenbarung, XIII, 362-363.

[33] „Diese Notwendigkeit ist bei den Alten, insofern sie unter den ersten bestimmenden Mächten des Weltalls ist, keineswegs eine blinde, mechanische, sondern - wie Aristoteles sagt die unbewegliche Wesenheit oder der Gott selbst als unbewegliche Wesenheit, der Gott selbst, insofern er selbst nicht beweglich alles bewegt. Nun eben dieses an sich Unbewegliche ist das Gesetz, und demnach stimmt jener aristotelische Begriff der Notwendigkeit ganz überein mit dem Begriff des Gesetzes" (Initia Ph. U., 112).

[34] „Denn, wenn das Seinkönnende im Inneren bliebe, dann wäre das Bewegliche mit ihm gefesselt, und es gäbe dann keine Zweideutigkeit ... Wenn also das Seinkönnende im Innern bliebe, so gäbe es auch keine Zeit. Dann wäre die Zeit das (blos) Verborgene, Innere; die Ewigkeit dagegen das Äussere, Offenbare; während jetzt umgekehrt die Ewigkeit das Verborgene, Innere, Ideale u. die Zeit das Offenbare, Äussere ist ... denn es war die Frage, welches das Innere und welches das Äussere ist. Auf das Seinkönnende kam es an, ob die Zeit das Innere, Verborgene bleiben, die Ewigkeit das Äussere, Offenbare sein sollte u. umgekehrt" (Initia Ph. U., 115).

[35] „Das Seinkönnende ist das Bewegliche, die Beweglichkeit selbst“ (Initia Ph. U., 115). 
que se mueve o puede ser movido ${ }^{36}$. El implícito, pues, del razonamiento sería: sin lo movible no hay movimiento; por lo tanto, el móvil es un ingrediente del movimiento ${ }^{37}$; $\mathrm{y}$, si hubiera un movimiento que se redujera a su ingrediente móvil, entonces estaríamos ante un movimiento posible, pero no efectivo. En ese sentido, podría decirse que es inmóvil, no porque no se pueda mover, sino porque no es movido ni se mueve efectivamente.

Desde luego, para que todo lo anterior pueda compaginarse, hace falta distinguir dos tipos de movimiento real, uno primero que se reduzca al móvil (rotatorio), y otro que esté condicionado por este primero (rectilíneo). Pero eso no basta. Para poder justificar la existencia real y contemporánea de los dos, haría falta, además, que uno de ellos fuera perfecto y el otro no, de manera que el no perfecto recibiera su sentido a partir del perfecto ${ }^{38} ; \mathrm{y}$, adicionalmente, que los dos movimientos distinguidos realmente estuvieran también en sujetos distintos. Sin embargo, Schelling pretende que ambos movimientos tengan un mismo sujeto (Dios-voluntad durmiente).

Aparte de otras que señalo más adelante, las diferencias con Aristóteles, invocado por él, son patentes, no sólo porque para el estagirita el movimiento rectilíneo no es perfecto, sino porque el mero movimiento implica para él potencia o imperfección, cosa impropia de Dios. Además, la distinción entre ambos movimientos, establecida por Schelling en términos de condición de posibilidad y efectividad, implica que no podrían estar, a la vez, en el mismo sujeto sin contradecirse, por lo que difiere de aquél también en la importancia concedida al principio de contradicción ${ }^{39}$.

Con todo, podría justificarse esa aproximación al motor inmóvil aristotélico, por parte de Schelling, aduciendo que, según éste, el movimiento rotatorio funciona en su (relativa) inmovilidad como la causa final que atrae a todos los

[36] Aristóteles llama «inmóvil», propiamente, sólo a lo que no puede moverse en absoluto, mientras que llama «quieto» a lo que, siendo movible o pudiendo moverse, no es movido ni se mueve (cfr. Metaph XI, c. 12, 1068b22-24). Schelling no sólo unifica esos dos sentidos (inmóvil y quieto), sino que pretende que lo que se mueve rotativamente sea inmóvil.

[37] Esto es falso, cuando se habla del movimiento puro. La referencia al móvil sólo es necesaria cuando el movimiento es considerado como algo extrínseco y accidental. Si se considera el movimiento puro, el móvil no entra en su noción.

[38] Y eso es lo que, como se verá más adelante, dice Schelling, pero cambiando el sentido obvio de las cosas, porque él propone que el movimiento perfecto es el temporal-rectilíneo, mientras que el imperfecto es el eterno: el movimiento condicionado es el que, según él, daría sentido al incondicionado.

[39] Schelling admite el principio de contradicción en sentido estricto (Weltalter. Bruchstück, SW VIII, 214-215), pero no lo entiende como el principio más alto o primero (Darstellung des Naturprocesses (1843/44), SW X, 304-306), sino que, como señalo más adelante, lo subordina al principio de identidad de ser y pensar, traicionando así su voluntad de realismo. 
tiempos y hacia la que se dirigen todos ellos ${ }^{40}$. Lo movible sería lo que atraería con su posibilidad (de moverse) al movimiento, y, por consiguiente, tendría la función del motor aristotélico. Al suponer esto, se adivina la jugada: el movimiento reducido a móvil haría las veces (finales) del motor inmóvil. Y precisamente eso es lo que la circularidad del movimiento facilitaría al pensamiento, pues un movimiento rotatorio tiene realmente -por ser movimiento- principio, medio y fin, pero sin que ninguno de esos momentos pueda ser determinado cognoscitivamente en concreto, de manera que cabe pensarlo como motor, móvil y movimiento, las tres cosas a la vez ${ }^{41}$. De ahí que él pretenda que pueda ser, a la par, movimiento e inmovilidad.

Pero, a su vez, para que eso tenga algún sentido es preciso pensar el movimiento circular como una reflexión: un movimiento que recayera sobre sí mismo se convertiría a sí mismo en móvil y en motor de su propio moverse ${ }^{42}$. Así podría ser pensado como las tres cosas a la vez. Si uno se preguntara por qué ha elegido Schelling, entre los movimientos circulares, la rotación y no los movimientos orbitales, puede encontrar aquí la respuesta más profunda: el movimiento rotatorio es el que puede ser representado (imaginado) como reflexivo ${ }^{43}$. Sólo que en tal posibilidad salta a la vista la confusión entre lo físico (rotación) y lo pensado (reflexión), pues -en Aristóteles, y en la realidad físicael movimiento no se mueve ${ }^{44}$.

[40] „Alle Bewegung hat nur die ewige Unbeweglichkeit zum Ziel, und es ist alle Zeit, auch jene ewige Zeit, nichts anderes als die beständige Sucht nach der Ewigkeit." (Weltalter. Bruchstück, SW VIII, 235).

[41] „So verhält es sich nicht, sondern, weil keine der drei Gestalten ohne die andere etwas ist, so ist wie mit einem Zauberschlag - wie im Nu oder im Blitz - das Ganze gesetzt. Diess verhindert nicht, dass innerhalb dieses magischen Kreises Anfang, Mittel und Ende sey. Der Anfang darf nur nicht vor und ausser dem Ende, das Ende nicht vor und ausser dem Anfang, aber zugleich mit dem Ende darf der Anfang und zugleich mit dem Anfang das Ende gedacht werden. (Ph. d. Offenbarung, XIII, 258-259).

[42] Aunque puede ser pensado, eso no tiene sentido físico. Para Aristóteles, el movimiento circular repercute como fin hacia fuera de él, convirtiéndose en motor respecto de otros movimientos. Pero un motor de sí mismo no es más que una versión de la causa sui espinosiana, en la que se mezcla la causalidad (física) con el pensamiento (Ethica, II, Definitio I, Spinoza Opera, C. Gebhardt, II, 45).

[43] Los filósofos antiguos centraban su atención en los movimientos orbitales, porque pensaban a Dios como inmóvil, y consideraban que el movimiento principal de los astros se daba alrededor de lo inmóvil. Aunque, al poner el movimiento en Dios, Schelling ha de elegir, sin duda, aquel movimiento que parece menos dependiente, o sea, el de rotación, eso no obstante, el movimiento rotatorio sólo puede ser pensado como infinito si es imaginado como reflexivo.

[44] Ése es el implícito de la reducción del movimiento a móvil: reducido a móvil, sería un movimiento que se mueve. Según Aristóteles, lo que se mueve es el móvil. Por eso decía él que todo lo que se mueve (móvil) es movido por otro (motor), sin que ni móvil ni motor sean 
Como se ve, tal como acabo de decir que piensa Schelling el movimiento rotatorio, la diferencia de cualidad real con el movimiento del concepto en Hegel quedaría anulada: tan meramente pensado es el movimiento del concepto como este movimiento rotatorio puro; por lo que, si bien la similitud de su filosofía negativa con la de Hegel adquiere cierto incremento ${ }^{45}$, el pretendido efecto reflexivo de la rotación le haría perder, en cambio, efectividad realista.

\section{Problemas IMPLÍ́CITOS EN LA CONCEPCiÓN DE LOS EONES ETERNOS}

La diferencia entre la eternidad, o vida divina, y el tiempo, o creación, no puede reducirse a la mera diferencia entre el movimiento circular y el movimiento rectilíneo. Por muy infinito que fuere, el tiempo nunca es la eternidad. El movimiento circular no es eterno, pues no por ser circular deja de ser movimiento, y la noción misma de movimiento implica comienzo: puede existir un movimiento sin fin, pero no un movimiento sin comienzo ${ }^{46}$. La eternidad, sin embargo, no sólo es sin fin, también es sin comienzo. De ahí la (insoluble) dificultad que representa para Schelling conciliar la eternidad con el comien$\mathrm{zo}^{47}$, y que queda reflejada en su noción de «eones», o tiempos eternos ${ }^{48}$. La eternidad no puede ser de otra manera más que una y simple, por eso resulta contradictorio mezclarla con la pluralidad de los eones, los cuales, por supuesto,

el movimiento. Pretender que el movimiento sea también móvil y motor constituye un ejemplo paradigmático del monumental enredo en que termina la filosofía idealista, y que no puede ser resuelto mientras no se advierta que el mover-se del movimiento no es más que el resultado de la intromisión reflexiva del pensamiento en el mundo extramental. Ni en el pensamiento existe el movimiento, ni en el movimiento el pensamiento, sea éste reflexivo o no.

[45] De su propia filosofía de la identidad dice Schelling: „Mithin ist die ganze Vorstellung jenes Processes und jener Bewegung eine selbst illusorische, es ist eigentlich nichts geschehen, alles ist nur in Gedanken vorgegangen, und diese ganze Bewegung war eigentlich nur eine Bewegung des Denkens“ (Zur Geschichte, SW X, 124-125).

[46] El movimiento puro implica comenzar y no cesar (Cfr. L. Polo, Curso de Teoría del Conocimiento IV, OC VII, 329), es decir, una cierta secuencia antes-después (inacabable), y, por eso, implica composición, o sea, falta de simplicidad; en cambio, la eternidad inmutable sólo puede corresponder a lo simple.

[47] „- Wer Zeit und Ewigkeit begreifen will, muss über Zeit und Ewigkeit hinausgehen. Deswegen finden auch alle die Philosophen, die gleich von der wahren Ewigkeit anfangen, die grössten Schwierigkeiten, weil sie die Ewigkeit wieder aufheben müssen, um die Zeit setzen zu können. Aber die wahre Ewigkeit ist die, welche nie aufgehoben, nie Vergangenheit werden kann“ (Initia Ph. U., 115).

[48] „Diese drei Zeiten sind die wahren chrónoi aionioi, ein bekannter Ausdruck, der übersetzt werden kann «die ewigen Zeiten» im Gegensatz der vergänglichen, auf einem zufällig Seienden beruhenden Zeit der gegenwärtigen Welt. Der Ausdruck kann aber auch übersetzt werden: «Weltzeiten» (aiones), und so ist das System dieser Zeiten = dem System der Weltzeiten oder «Weltalter»; und weil das vorgetragene Ganze auf dieses System hinführt, habe ich das Ganze selbst das System der Weltalter genannt" (Grundlegung, 487). 
serían distintos del tiempo ordinario (que se repite), pero en última instancia serían tiempos ${ }^{49}$, y, por tanto, sucesivos (antes-después). La eternidad anterior a la creación se convierte, según Schelling, en tiempo pasado por el advenimiento del tiempo presente, que era futuro para el anterior y será pasado para el futuro ${ }^{50}$. Ahora bien, si esos eones son sucesivos, porque el tiempo verdadero es la secuencia de los tiempos ${ }^{51}$, entonces ninguno de ellos permanece, ¿cómo podrán, pues, ser eternos? Es verdad que Schelling pretende que cada uno de los tiempos por separado sea imagen del tiempo entero ${ }^{52}$, pero él mismo afirma que sólo el último (futuro) es el tiempo entero, y el que organiza a los otros dos ${ }^{53}$.

¿Qué será el eón futuro: tiempo o eternidad? Si fuera temporal, comenzaría, pasaría y se acabaría; si fuera eterno, ni comenzaría, ni pasaría ni se acabaría. O, dicho de otro modo también acorde con las expresiones de Schelling: si se moviera rectilíneamente, sucedería a otro y sería sucedido por otro; si se moviera circularmente, ni sucedería a otro ni sería sucedido por otro; ¿cómo, pues, se moverá ese tiempo futuro: rectilínea o circularmente?, pues no puede moverse de ambas maneras a la vez.

La noción del eón futuro es sumamente problemática, porque no se ve cómo podrá seguir siendo tiempo, dado que, por ser el último, no puede ser convertido en pasado ni ser sucedido por otro eón, de modo que, siendo -según Schelling- el presente el que introduce el tiempo verdadero ${ }^{54}$, sólo caben dos

[49] „So ist es also nur der Widerspruch in der höchsten Steigerung, der die Ewigkeit bricht und statt der Einen Ewigkeit eine Folge von Ewigkeiten (Aeonen) oder Zeiten setzt. Aber eben diese Folge von Ewigkeiten ist es, was wir insgemein die Zeit nennen. In dieser Entscheidung also schliesst sich Ewigkeit in Zeit auf" (Weltalter. Bruchstück, SW VIII, 302). Cfr. Grundlegung, 486-487. Nótese que el propio Schelling lo considera una contradicción.

[50] Grundlegung, 88-89; Ph. d. Offenbarung, SW XIV, 109

[51] „Denn die wahre Zeit ist nicht Eine, sich immer wiederholende Zeit, sondern selbst eine Folge von Zeiten“ (Ph. d. Offenbarung, SW XIV, 110). Cfr. Einleitung i.d.Ph. D. Mythologie, SW XI, 235

[52] Weltalter. Fragmente, 81. Schelling piensa que el eón pasado es el mundo, y que el eón presente es la humanidad, y parece que el futuro los contendría a ambos. Para eso haría falta que ambos fueran inacabables o permanentes -lo que contradiría su carácter temporal-, y, en tal caso, lo que no tendría sentido sería el futuro. Pues si el hombre (presente) no elimina al mundo (pasado), ni al revés, y ambos permanecen para siempre, el futuro sería la mera continuación de uno y otro, no el tiempo entero ni el final de los otros dos.

[53] „Die ganze Zeit aber ist die Zukunft“ (Weltalter. Fragmente, 82). Cfr. Grundlegung, 486-487; Ph. d. Offenbarung, SW XIII, 375.

[54] Grundlegung, 486-487: "Die wahre Zeit ist A+B+C. Denken Sie sich in dieser Reihe zuerst A gesetzt, so ist dieses A für sich allein noch nicht in der Zeit; erst indem B hinzukommt, wird es zur Zeit; es wird zur Vergangenheit gegen B. Vor dem Hinzukommen dieser Zeit war A nicht Zeit, also relativ Ewigkeit; erst indem die zweite Zeit, B, hinzukommt, erst jetzt entsteht wirklich Zeit, welche A+B ist. Denken Sie sich, dass die Zeit und auch die Welt auf diese Weise 
posibilidades: o bien que ese eón futuro carezca de presente, o bien que su presente no introduzca, a su vez, un pasado y un futuro, es decir, que no vaya a ser en ningún caso como el presente que conocemos. Por tanto, un eón sin presente temporizante no sería tiempo ni sería compatible con la conciencia ${ }^{55}$. Dicho de otro modo, el eón futuro no podría, por ser último, ser el tiempo entero, si es que el tiempo es necesaria y verdaderamente pasado, presente, futuro ${ }^{56}$; $y$, por otra parte, tampoco podría no ser tiempo, ya que, según Schelling, sólo es perfecto lo temporal ${ }^{57}$. ¿Podrá, entonces, el eón futuro ser la eternidad? ¿Qué habría de pasar para que el eón futuro no deje de ser tiempo y, a la vez, sea eterno?

Para intentar hacer frente a estos problemas, recurre Schelling a la distinción entre dos formas de eternidad, ambas complementarias: una eternidad negativa, entendida como quod fine et initio caret, y una eternidad positiva, enunciada como el comienzo que no tiene comienzo y el final que no tiene fin ${ }^{58}$. La noción de la que él llama eternidad negativa (quod initio et fine caret) está tomada de la filosofía medieval ${ }^{59}$, sólo que los medievales no hacían valer el «caret» como negatividad, sino como mera aclaración de la positiva inmutabilidad de Dios, mientras que Schelling lo toma al pie de la letra, es decir, como carencia de algo $^{60}$; tanto es así, que esa eternidad (negativa) es interpretada como

wirklich angefangen hat, dass ein vorausgegangenes Moment, das, solange es allein = der Ewigkeit ist, durch einen nachfolgenden als Vergangenheit und dieser als Gegenwart gesetzt ist, sodass eodemque actu Vergangenheit und Zukunft zugleich entstanden“.

[55] "Besondere Schwierigkeit aber hat für den tiefer Denkenden die Erklärung, wie das Ewige sich seiner Ewigkeit bewusst werden könne, obschon die meisten leichten Fusses darüber hingehen. In der leeren, abgezogenen Ewigkeit lässt sich überall kein Bewusstseyn denken; das Bewusstseyn der Ewigkeit kann sich nur aussprechen in jenem Wort: Ich bin, der da war, der da ist, und der da seyn wird ... Das Bewusstseyn einer solchen Ewigkeit ist ohne eine Unterscheidung von Zeiten unmöglich“ (Weltalter. Bruchstück, SW VIII, 263-264).

[56] “...denn Zeit ist erst gesetzt, wenn Vergangenheit, Gegenwart und Zukunft gesetzt ist" (Ph. d. Offenbarung, SW XIV, 109).

[57] Cfr. nota 61 de este trabajo.

[58] “...der Satz: in Gott sey weder Anfang noch Ende, heisst in Bezug auf das göttliche Seyn nur so viel: in Gott ist kein Anfang seines Anfangs und kein Ende seines Endes. Diess erst ist der positive Begriff des Ewigen und der Ewigkeit, während jene gewöhnliche Formel: Aeternum est, quod fine et initio caret, nur der negative Begriff der Ewigkeit ist" (Phil. der Mythologie, SW XII, 43). Cfr. Weltalter. Fragmente, 199-200.

[59] Cfr. Tomás de Aquino, Contra gentiles I, c. 15: Nam omne quod incipit esse vel desinit, per motum vel mutationem hoc patitur. Ostensum autem est Deum esse omnino immutabilem. Est igitur aeternus, carens principio et fine").

[60] „In diesem beständigen Umtrieb hebt sich natürlich der Unterschied des Höheren und Niederen wieder auf; es ist weder ein wahrhaft Oberes noch ein wahrhaft Unteres, weil abwechselnd das eine Oberes und das andere Unteres ist, sondern nur ein unablässiges Rad, eine nie stillstehende rotatorische Bewegung, in der keine Unterscheidung ist. Auch der Begriff des Anfangs, wie der des Endes, hebt sich in diesem Umlauf wieder auf. Es ist wohl ein Anfang der 
imperfección, en antítesis con el tiempo, que sería la perfección ${ }^{61}$. En función de dicha interpretación, parece que la eternidad negativa podría igualarse, en el pensamiento de Schelling, con la eternidad de la vida interna del sujeto absoluto. Pero el problema es que, entonces, esa eternidad negativa se acabaría con la decisión inmemorial, lo que constituiría una contradicción ${ }^{62}$ : sería una eternidad que se acaba.

A su vez, la noción de la mencionada eternidad positiva-el comienzo que no tiene comienzo y el final que no tiene fin-introduce de rondón un comienzo y un final en Dios ${ }^{63}$, a los que pretende quitar mordiente restrictivo duplicándolos negativamente, es decir, utilizando también la negación, si bien referida ahora a la limitación temporal. Pero atendamos a la explicación que da Schelling.

La eternidad positiva, aquella que no tiene comienzo de su comienzo ni final de su final, es la verdadera vida de Dios, la cual, como toda vida, es un devenir, un movimiento ${ }^{64}$. ¿Cuándo se da ese devenir de modo más intenso? En el momento de la creación, pues en ese instante se introduce el mayor cambio en la vida divina, la cual pasa de estar recluida en su interior (eterno) a exteriorizarse (temporalmente). Puesto que ese momento concreto del devenir tiene como punto de partida una eternidad (negativa), se puede decir que no tiene comienzo. E, igualmente, como su término final está siempre llegando

Potenz, der Möglichkeit nach darin, etwas, das Anfang seyn könnte, aber nicht wirklicher Anfang ist. Wirklicher Anfang ist nur ein solches, das sich selbst setzt als nicht seyend in Bezug auf das, das eigentlich seyn soll. Aber das, was Anfang in dieser Bewegung seyn könnte, erkennt sich nicht als Anfang, und macht mit den andern Principien gleichen Anspruch das Seyende zu seyn" (Weltalter. Bruchstück, SW VIII, 229). Nótese que el texto sostiene la existencia de un comienzo -y de un final- en el movimiento rotatorio divino, pero que no sería efectivo comienzo, porque no podría ser reconocido como tal.

[61] Phil. der Mythologie, SW XII, 43: “'Ohne Anfang und ohne Ende zu seyn, ist keine Vollkommenheit, sondern unvollkommen, ist Negation alles Actus; denn wo Actus ist, da ist Anfang, Mittel und Ende. ... in jedem Actus, in jeder Bewegung sind aber nur drei Momente oder Zahlen wesentlich, Anfang, Mittel und Ende; was also diese in sich selbst hat, ist ganz vollendet“. Cfr. Weltalter. Fragmente, 199; Grundlegung, 420.

[62] Cfr. nota 149 de este escrito.

[63] Lo cual es contradictorio con la noción de eternidad pura.

[64] „Denn Gott ist kein todtes, stillstehendes Wesen, sondern lebendig, ja das höchste Leben selbst. ... Nun ist ja kein Leben ohne Werden u. Bewegung, also auch nicht das göttliche Leben, noch Gott selbst sofern er Leben ist. Es ist freylich ein ewiges Werden, d.h. ein Werden, das von Freyheit geworden ist u. noch immer wird u. immer werden wird (denn ich muß fast undeutlich reden - weil auch das was ein ewiges Werden sey, nicht mehr verstanden wird in der jetzigen Überspannung der Begriffe); aber ewig oder nicht ewig, ein Werden ist immer ein Werden. Kein Leben u. Werden u. sich Bewegen ist ohne Anfang u. ohne Ende. Also auch nicht das Leben Gottes, ja Gott selbst sofern er ein Leben ist“ (Weltalter. Fragmente, 199). 
a ser, se puede decir que tiene un final eterno, un fin sin final, o sea: que no cesará nunca de devenir. Si se diviniza el devenir ${ }^{65}$, entonces el devenir será la eternidad, y a eso le llama Schelling la eternidad positiva ${ }^{66}$.

Gracias a la entronización en Dios del devenir, puede pensar y sostener Schelling que eternidad y tiempo coexisten, y no de forma separada, sino unitariamente ${ }^{67}$. Gracias a eso también, cree poder resolver el problema de la conciencia en Dios: Dios no es ni sólo inconsciente ni sólo consciente, sino las dos cosas a la vez, pues es el que eternamente deviene consciente ${ }^{68}$.

Sin embargo, con este planteamiento se introducen graves problemas. Ante todo, la noción de un devenir eterno es como un hierro de madera ${ }^{69}$, o, dicho con más adecuación, como una simplicidad indefinidamente compuesta. Además, al poner el énfasis en el momento estricto de la coexistencia de eternidad y tiempo, tanto la situación anterior como la siguiente quedan despojadas de sentido. Desde luego, la vida divina interna pensada por Schelling como previa a la decisión inmemorial queda sin sentido, tan falta de sentido como lo sería un Dios que dejara de ser Dios. Y, por su parte, también queda sin sentido la diversidad de los eones: si Dios fuera realmente el werden, entonces todo será por igual werden, sin que cupieran diferencias entre el pasado, el presente y el

[65] „Ich habe dir schon gesagt, daß mir das Leben Gottes ein ewiges Werden ist. Wenn dann nun aber das Seyn Gottes gleich ist einem (wiewohl ewigen) Werden, so ist es auch gleich einem (wiewohl ewigen) Übergang aus Nichtseyendseyn in Seyendseyn" (Weltalter. Fragmente, 200).

[66] „Es ist freylich ein ewiger Anfang, d.h. daß dieß Werden von aller Ewigkeit so angefangen hat $u$. noch immer anfängt $u$. nie aufhören wird anzufangen. So ist sein Ende auch ein ewiges Ende, d.h. $<$ daß Gott $>$ Gott ist nicht ein Ohnendliches wie man zu denken pflegt, sondern ein ewig (daß ich handgreiflich rede) zu Stande gekommenes u. noch immer zu Stande kommendes, u. das nie aufhören wird zu Stande zu kommen, <d.h. wahrhaft Gott zu seyn. $>$ Also daß es nur grob geredet ist, wenn gesagt wird, Gott sey ohne Anfang u. Ende, da man dafür sagen sollte, er sey ohne einen Anfang seines Anfangs u. ohne Ende seines Endes, d.h. daß er ewig anfange u. ewig ende" (Weltalter. Fragmente, 199).

[67] Weltalter. Bruchstück, SW VIII, 307; Ph. d. Offenbarung, SW XIII, 308-309.

[68] „Nun ist freilich nicht zu denken, dass Gott eine Zeitlang bewusstlos gewesen, dann bewusst geworden sey; wohl denkbar ist aber, dass in demselbigen untheilbaren Akt des Bewusstwerdens zumal das Bewusstlose und das Bewusste von Gott gefasst worden, dieses als das ewig Gegenwärtige, jenes aber mit der Bestimmung des ewig Vergangenen ... / Das Bewusstseyn besteht nur im Akt des Bewusstwerdens, und so lässt sich auch in Gott nicht ein ewiges Bewusstseyn, nur ein ewiges Bewusst-werden denken" (Weltalter. Bruchstück, SW VII, 262-263).

[69] Schelling se da cuenta de que tiempo y eternidad no se pueden mezclar: "Ein ewiges Geschehen ist aber kein Geschehen" (Zur Geschichte, SW X, 124), pero sigue intentando ponerlos en fila india. 
futuro, pues no tendría sentido decir «devino» o «devendrá», sólo lo tendría decir «deviene».

Pero atendamos en directo a la propia noción de eternidad positiva. ¿Qué significa un comienzo sin comienzo, o un final sin final? Si se entiende literalmente, un comienzo sin comienzo es un comienzo que no comienza; pero si no comienza, no es comienzo; por tanto, un comienzo sin comienzo es una contradicción in adjecto. Lo mismo acontece con un final sin final: no es final alguno. Para poder darle algún sentido a la noción de eternidad positiva tiene Schelling que elucubrar mucho. Veámoslo.

En primer lugar, y después de haber sostenido que también el movimiento rotatorio infinito, o la vida interna de Dios que precede a la creación, tuvo un comienzo $_{(1)}{ }^{70}$, Schelling, para poder pensar que la eternidad positiva no tiene un comienzo de su comienzo ${ }_{(2)}$, se ve precisado a calificar de verdadero comienzo al comienzo $_{2}$, y de no verdadero comienzo al comienzo ${ }_{1}$ ¿ Qué es, pues, lo que hace verdadero a uno y no al otro? La respuesta es ésta: que el comienzo verdadero es aquel que no vuelve siempre a comenzar de nuevo, sino que persiste ${ }^{71}$. Por tanto, se concluye que el comienzo ${ }_{1}$ no es verdadero porque, en vez de persistir como comienzo, siempre está comenzando de nuevo; mientras que el werden sería el comienzo verdadero, puesto que nunca terminaría de llegar a ser. Dejando a un lado ciertas cuestiones obvias -cuales son: ¿por qué, si el comienzo no es verdadero, lo considera y llama comienzo?, y ¿cómo si el comienzo ${ }_{2}$ es el verdadero comienzo, puede decir que es sin comienzo, o sea, que no comienza?-, seguiré acompañando a Schelling en sus elucubraciones.

Pues bien, para poder pensar que la eternidad positiva tiene un comienzo sin comienzo haría falta sostener que, en realidad, ella habría comenzado efectivamente con la decisión inmemorial, pero como el comienzo ocurrió sin saberlo ${ }^{72}$, entonces se puede pensar que éste no comenzó. Y eso es lo que sugieren los textos: el comienzo no es verdadero comienzo, porque lo que podría ser comienzo en su movimiento no es reconocido como comienzo ${ }^{73}$. Por tanto, cuando dice «verdadero» $\mathrm{o}$ «no verdadero comienzo» lo que nos está diciendo

[70] Cfr. nota 60 de este escrito.

[71] „Wahrer Anfang ist der, der nicht immer wieder anfängt, sondern beharrt“ (Weltalter. Bruchstück, SW VIII, 229). Esta afirmación es profundamente verdadera, pero no puede ser hecha respecto de Dios ni de su eternidad, ni siquiera de cualquier comienzo, sino que ha de ser hecha sólo respecto del ser o comienzo real del mundo, cfr. L. Polo: "La persistencia de la actividad es el sentido trascendental de lo que se llama comienzo" (El Ser I, OC III, 147).

[72] „die Ewigkeit also ist sich ihrer nicht bewußt“ (Weltalter. Bruchstück, SW VIII, 136)

[73] „Aber das, was Anfang in dieser Bewegung seyn könnte, erkennt sich nicht als Anfang" (Weltalter. Bruchstück, SW VIII, 229). 
es «comienzo conocido o no conocido como comienzo». Pero eso implica que no saber cuándo empezó es equivalente a no haber empezado verdaderamente ${ }^{74}$. La falta de conciencia de la voluntad durmiente sería la razón de que su movimiento circular, habiendo tenido un comienzo, no sea verdadero comienzo; y, en cambio, la conciencia que acompaña al acto de querer sería la razón de que la creación sea el comienzo verdadero de la eternidad positiva de Dios ${ }^{75}$.

En segundo lugar, para poder pensar que la eternidad positiva no tiene un final de su final, distingue Schelling, igualmente, un final verdadero y otro no verdadero. El final verdadero, para él, es sólo aquel que no necesita retornar al comienzo ${ }^{76}$; luego el no verdadero será aquel que retorna al comienzo. Con eso rechaza a Hegel, y excluye que el eón futuro vuelva al eón pasado, lo cual concuerda con su noción de eternidad verdadera, a saber, la que nunca puede ser suprimida, ni puede ser convertida en pasado ${ }^{77}$. Pero como todas las determinaciones de la eternidad positiva tienen forma de negación ${ }^{78}$, no queda claro en qué sentido ese final es un final positivo. A ese respecto, la noción de final verdadero que sugiere Schelling es la de aquel final con el que se alcanza el objetivo, aquel final que lo realiza ${ }^{79}$; por tanto, el final no verdadero parece que debería ser aquel que no acabara nunca, porque nunca alcanzara su objetivo $^{80}$. Y, sin embargo, no está claro ni lo uno ni lo otro. Para ser más preciso, su propuesta es, literalmente, que el final sin final sería un eterno haber llegado a ser Dios (pasado), y un siempre estar llegando a ser Dios (presente), y un

[74] Y, puesto que somos nosotros los que no sabemos cuándo empezó, «verdadero» significa «sabido por el hombre». Cfr. nota 97.

[75] Con ese razonamiento podríamos sostener que cualquiera de nosotros, los humanos, somos positivamente eternos, puesto que, aunque hemos sido concebidos y hemos nacido, puesto que no somos conscientes de ninguna de las dos cosas, nuestro comienzo es un comienzo sin comienzo.

[76] „Ebenso ist nur das wahrhaftes Ende, worin ein Wesen besteht, von dem es nicht wieder auf den Anfang zurückzugehen braucht“ (Weltalter. Bruchstück, SW VIII, 230).

[77] „Aber die wahre Ewigkeit ist die, welche nie aufgehoben, nie Vergangenheit werden kann“ (Initia Ph. U., 115)..

[78] Esas determinaciones son: no necesita retornar al comienzo, no puede ser suprimida y no puede ser convertida en pasado.

[79] „Gott ist nicht ein Ohnendliches wie man zu denken pflegt, sondern ein ewig (daß ich handgreiflich rede) zu Stande gekommenes u. noch immer zu Stande kommendes, u. das nie aufhören wird zu Stande zu kommen, <d.h. wahrhaft Gott zu seyn" (Weltalter. Fragmente, 199).

[80] Ahora bien, la noción de devenir sugiere esto último, sobre todo porque si el devenir fuera el ser de Dios, o la entraña misma de la realidad, entonces no podría tener objetivo alguno: sería el devenir por el devenir. 
nunca cesar de llegar a ser verdaderamente Dios (futuro) ${ }^{81}$. En tal propuesta se observa que la meta parece ser alcanzada ya con el primer eón, o eón pasado, e igualmente con el segundo (presente) y tercer eón (futuro). Pero, si se alcanzara la meta ya en el primero, ¿para qué hacen falta los otros dos eones? $\mathrm{O}$, si en realidad el verdadero Dios es el que nunca cesa de estar llegando a ser Dios, es decir, el eón futuro, entonces ¿para qué hacen falta los dos primeros eones? Y, sobre todo, ¿qué sentido tiene estar siempre llegando a ser Dios? Eso implicaría nunca llegar a serlo del todo; por tanto, más que un final sin final, se trataría de un final que nunca llega a ser final. En cualquier caso, lo que parece claro es que pasado, presente y futuro no serían más que el constante estar deviniendo (werden) de Dios, o sea, un único proceso con verdadero comienzo y con un final no alcanzado. Pero nada de eso es, o se parece, a la eternidad.

Si se me permite resumirla, lo nuclear de la propuesta de Schelling, sonaría así: la eternidad tiene comienzo, a saber, el comienzo del movimiento rotatorio, pero, como ese comienzo es inconsciente, no es propiamente lo que se llama un comienzo. El verdadero comienzo es el comienzo consciente, el que resulta de la decisión inmemorial, la cual es inmemorial porque es inconsciente, pero se vuelve consciente al interrumpir (inconscientemente) la circularidad de su movimiento y transformarse en temporalidad rectilínea. Dicha temporalidad es el final de la eternidad negativa, un final que ya no vuelve a repetirse, $y$, por eso, implica el final verdadero del movimiento circular ${ }^{82}$, aquel durante el cual Dios no era como Dios todavía ${ }^{83}$, pues no había llegado a ser verdaderamente Dios. El verdadero comienzo de Dios es el comienzo del eón presente, cuyo advenimiento ha convertido en eón pasado al movimiento circular puro. Ahora bien, como el eón presente comienza y sigue en línea recta, entonces ha de ser seguido por otro, el eón futuro, que, lógicamente, lo debería convertir a él en pasado -aunque eso llevaría consigo que no hubiera sido un verdadero comienzo, en abierta contradicción con el supuesto de partida ${ }^{84}$. Pero si se concede

[81] Cfr. nota 79.

[82] El verdadero final es el que no vuelve a comenzar, cosa que, en cambio, hace el movimiento circular. Cfr. nota 76.

[83] Zur Geschichte, SW X, 100-101; 129-130. Aunque estos textos se refieren a la Naturphilosophie, pueden ayudar a entender las descripciones del movimiento del sujeto absoluto en su filosofía negativa.

[84] Si el verdadero comienzo es el que persiste y no da lugar a otro comenzar, para que fuera verdadero el comienzo del eón presente no debería haber ningún otro eón sucesivo. Si cede su lugar a otro eón (futuro), entonces habrá otro comienzo, pues en el sistema de los tiempos cada tiempo está limitado y difiere esencialmente de los otros, cfr. Einleitung i.d.Ph. D. Mythologie, SW XI, 235. 
hipotéticamente que, a pesar de que se deba convertir en pasado, el del eón presente sea un verdadero comienzo, y que el eón futuro, aun debiendo tener un comienzo propio, conserve el del eón presente, el panorama del conjunto sería el siguiente: el haber llegado a ser Dios, por parte del eón pasado, queda convertido en un estar llegando a ser Dios en el eón presente, y será un no cesar de estar llegando a ser Dios en el eón futuro ${ }^{85}$. En definitiva, para Schelling, el ser de Dios sería su devenir eterno-temporal, o sea, la historia de lo que ha ido y va siendo Dios ${ }^{86}$, lo mismo que el tiempo humano es concebido por él como la historia de lo que ha ido y va siendo el hombre. Todo lo cual es, cuando menos, patentemente obscuro, si no caótico ${ }^{87}$.

\section{CONCLUSIÓN: LOS IMPLÍCITOS ULTERIORES}

Llegados a este punto, conviene considerar cuanto se ha dicho antes. Los esfuerzos de Schelling por ofrecer una filosofía efectivo-realista frente al idealismo lógico de Hegel tropiezan, como se ve, con dificultades insolubles. Para pensar a Dios como principio absoluto, cree Schelling tener que pensarlo como dotado de movimiento rotatorio, pero, a la vez, se ve obligado a pensarlo como inmóvil; para pensar a Dios como viviente, cree tener que pensarlo como temporal, pero, a la vez, se ve obligado a pensarlo como eterno; para pensar a Dios cual voluntad pura y primera, tiene que pensarlo como durmiente o in-

[85] Cfr. nota 79. Cualquiera puede notar el sinsentido de que algo que ya haya llegado a ser empiece -después- a llegar a ser, y continúe-siempre- llegando a ser. En especial, si el devenir se eleva a la altura del ser, entonces carece de sentido decir de él que llegó a ser o llegará a ser: eso se puede decir de una cosa particular, pero no del ser.

[86] Zur Geschichte, SW X, 104. Ph. d. Offenbarung, SW XIII, 195; 494. El esquema historiforme de los eones concuerda perfectamente con la reducción del ser al werden o devenir. En Hegel el devenir coincide con el método dialéctico, pero el método dialéctico tiene una meta final: la autoconciencia absoluta. En cambio, Schelling propone un devenir sin final, sin autoconciencia absoluta, como si una serie infinita de conciencias parciales fuera lo mismo que la (con)ciencia perfecta. Con su generalización del werden Schelling pretende unificar la eternidad y el tiempo en una especie de historia de Dios.

[87] Espero que el lector se haya quedado tan sorprendido como yo ante el cúmulo de sinsentidos de este planteamiento, de los que reitero algunos: la eternidad (rotación y movimiento rectilíneo) tiene comienzo (i); si no se comienza conscientemente no hay verdadero comienzo (ii); el comienzo verdadero comienza por una decisión inconsciente (iii); al comenzar verdaderamente finaliza una eternidad (negativa): una eternidad se acaba (iv). La verdadera finalidad de la eternidad (negativa) era el tiempo presente, de manera que la verdadera finalidad de la eternidad era que se acabara, y el tiempo presente es el que da sentido a la eternidad (v). El verdadero ser no es el ser, sino el devenir, o sea, el llegar a ser (vi). Pero una vez que el tiempo presente ha llegado a ser, tiene que dejar de ser (vi), o, lo que es igual, tiene su sentido en el eón futuro. Ahora bien, el eón futuro es simplemente el no cesar de llegar a ser, o sea, la continuación del presente (vii). 
consciente, pero, a la vez, se ve obligado a pensarlo como volente y consciente; para pensar a Dios como todo tiene que pensarlo como perfecto o acabado, pero, a la vez, se ve obligado a pensarlo como imperfecto o inacabado. La yuxtaposición de todas esas nociones, opuestas contradictoriamente entre sí, determina que el Dios de Schelling no esté a la altura de la pura y perfecta simplicidad exigida por la noción de divinidad ${ }^{88}$; y por eso cree él encontrar la máxima unidad de lo divino en el gran momento de la creación, o decisión inmemorial, ya que sólo en ese momento todos esos opuestos se habrían dado simultáneamente. Mas, de ese modo, Dios -esto es, El que es- resultaría ser un puro devenir entre opuestos.

Ahora bien, resulta patente que la inmutabilidad no puede ser una modalidad de movimiento ${ }^{89}$, y que la eternidad no puede ser una modalidad de tiempo, ni viceversa. E, igualmente, es obvio que la perfección no puede ser una modalidad de la imperfección, y que la conciencia no puede ser una modalidad de la inconsciencia. Tampoco el movimiento circular es una modalidad del rectilíneo, ni la magia (poder oculto) es una modalidad del misterio ${ }^{90}$ (trascendencia), ni el ocurrir temporal mundano o la historia humana en general son modalidades de la historia de Dios.

Todas estas nociones, piedras fundamentales en el pensamiento del último Schelling, son nociones que están claramente forzadas, obligadas a presentarse, a la vez, como son y como no son, de manera que, reunidas, dan lugar a un caos nocional. Pero ¿qué es lo que las fuerza y distorsiona? Sin duda alguna, se trata de la voluntad de Schelling, quien confiesa que el filósofo ha de comenzar por una decisión de su voluntad ${ }^{91}$. Él ha captado que el camino a seguir después de Hegel debe ser cierto realismo, porque es mejor -pongo en cursiva los matices volitivos-, pero no ha podido acertar con su sentido y hacerlo viable

[88] „Alles kommt darauf an, jene Einheit in Gott zu fassen, die zugleich Zweiheit ist, oder umgekehrt die Zweiheit, welche zugleich Einheit ist. Wäre Gott mit seiner ewigen Natur einerlei oder an sie gebunden, so wäre nur Einheit. Wären beide völlig aussereinander und getrennt, so wäre nur Zweiheit. Aber der Begriff jener Einheit, die, weil sie eine freiwillige ist, eben darum eine Zweiheit einschliesst, ist diesen Zeiten völlig fremd. Diese wollen nur Einheit, und wollen in Gott nichts als Geist und lauterste Einfachheit wissen" (Weltalter. Bruchstück, SW VIII, 269).

[89] La quietud sí puede ser una modalidad de movimiento (físico): en realidad, en el universo nada es inmóvil, y la quietud no es más que la sincronización de dos movimientos, que relativamente están quietos entre sí. Pero eso no vale para la inmutabilidad, pues ésta es la ausencia de todo movimiento.

[90] Weltalter. Fragmente, 93.

[91] „...die Philosophie nur von einem Wollen anfangen kann“ (Grundlegung, 405). "Aber die Frage ist nun, auf welche Weise die von uns gewollte Wissenschaft -die positive PhilosophiePhilosophie ist, und auf welche sie Wissenschaft seyn wird“ (Ph. d. Offenbarung, SW XIII, 126). 
intelectualmente ${ }^{92}$, porque ha seguido manteniendo en lo básico los mismos planteamientos idealistas de sus comienzos.

En efecto, en uno de sus últimos escritos sigue proponiendo como ley suprema de la filosofía la ley de la unidad de ser y pensar ${ }^{93}$. Cree él que para que todo cambie basta con invertir el orden observado por Hegel y por él mismo en su filosofía de la identidad: si antes sostenía que lo primero en esa unidad era el Was (lo pensado o posible), ahora sostiene que lo preponderante es el Das (lo fáctico o efectivo) ${ }^{94}$. Sin embargo, en su planteamiento lo radical y decisivo no ha cambiado ${ }^{95}$. Schelling piensa que si, de alguna manera, puede representarse el movimiento como inmóvil, entonces el movimiento ha de ser también inmóvil; o que, si, de alguna manera, puede representarse la eternidad como tiempo, entonces el tiempo ha de ser también la eternidad, etc. La identidad de ser y pensar es entendida por él como una identidad dual -yo la llamé compleja ${ }^{96}$, pero tal que no puede existir nada que no esté en relación con el pensamiento

[92] Realismo significaba, para el Schelling joven, espinosismo, o sea, objetivismo (Phil. Briefe über Dogmatismus und Kriticismus [1795], SW I, 303 y 330; System d. trasc. Idealismus, SW III, 356; Darstellung meines Systems [1801], SW IV, 110)- Para el Schelling último, significa el ser, o sea, la fuerza y vigor de lo eterno (Weltalter. Bruchstück, SW VIII, 244). Pero sigue siendo panteísmo (Ibid.), es decir, objetivación de Dios.

[93] „Versuchen wir es auf diese Weise. Sagen wir, diese Nothwendigkeit sey die des Einsseyns von Denken und Seyn - diese sey das höchste Gesetz, und dessen Sinn dieser, dass was immer Ist auch ein Verhältniss zum Begriff haben muss, was Nichts ist, d.h. was kein Verhältniss zum Denken hat, auch nicht wahrhaft Ist“ (Über die Quelle der ewigen Wahrheiten, SW XI, 587).

[94] „Denn jenes dem Denken über das Seyn, dem Was über das Dass ertheilte Uebergewicht scheint mir nicht ein besonderes, sondern ein allgemeines Leiden der gesammten, glücklicher Weise von Gott mit unerschütterlicher Selbstzufriedenheit ausgerüsteten deutschen Nation zu seyn, die sich im Stande zeigt, eine so lange - lange Zeit, unbekümmert um das Dass, mit dem Was einer Verfassung sich zu beschäftigen“" (Über die Quelle, SW XI, 589).

[95] Si bien Schelling quiere priorizar al ser (realismo) sobre la posibilidad (potencias), lo cierto es que ya antes ha puesto a éstas en el sujeto absoluto como materia original suya meramente posible: "Subjekt, Objekt, Subjekt-Objekt: das sind die Urstoffe des Seyenden. Aber nicht das Seyende, sondern das was das Seyende ist, ist der Gegenstand, ist das Gewollte, der Zweck, ist das Princip, das es wirklich ist (die andern sind bloß mögliche)" (Einleitung i. D. Ph. D. Mythologie, SW XI 319-320). Aunque considere que lo real-efectivo es más importante, para él la idea, lo meramente pensado o posible, no deja de anteceder al ser (O.c., SW XI, 392-393).

[96] I. Falgueras, La 'res cogitans' en Espinosa, Eunsa, Pamplona, 1976, en especial pp.142-143, 146-147, y 175-176. El último Schelling quiere seguir manteniendo la causa sui, aunque duplicándola en causa sui inmanente (sujeto absoluto), y causa sui transitiva (decisión inmemorial), y haciendo a la inmanente causa de la transitiva. Pero ¿qué sentido tiene que la causa sui deje de ser inmanente y se haga transitiva? Ninguno. Una causa sui absoluta que se haga transitiva es como un círculo que se hiciera cuadrado. ¿Podría convertirse un círculo, por virtud de su circularidad, en un cuadrado? 
(humano) ${ }^{97}$. En este sentido, el supuesto supremo de la filosofía de Schelling es el siguiente: "lo que se sabe ha de saberse enteramente y por completo; no hay ningún saber a medias, o mejor, un saber a medias no es saber alguno" 98 . Aunque el gran cambio introducido en 1811, con su (relativa) apertura a la revelación y a la trascendencia, podría haber conseguido corregirlo ${ }^{99}$, ese gran supuesto se mantiene vigente en su pensamiento ${ }^{100}$, hasta el punto de que se atreve a

[97] „...dass was immer Ist auch ein Verhältniss zum Begriff haben muss, was Nichts ist, d.h. was kein Verhältniss zum Denken hat, auch nicht wahrhaft Ist. / Gott enthält in sich nichts als das reine Dass des eigenen Seyns; aber dieses, dass er Ist, wäre keine Wahrheit, wenn er nicht Etwas wäre - Etwas freilich nicht im Sinn eines Seyenden, aber des alles Seyenden -, wenn er nicht ein Verhältniss zum Denken hätte, ein Verhältniss nicht zu einem Begriff, aber zum Begriff aller Begriffe, zur Idee. Hier ist die wahre Stelle für jene Einheit des Seyns und des Denkens“ (Über die Quelle, SW XI, 587). Pero el concepto de todos los conceptos, o idea, está al alcance del hombre: "Ich sage: er ist der Begriff aller Begriffe; denn jeder Gegenstand wird von mir nur gedacht, inwiefern ich das Seyende in ihm denke, der letzte Inhalt jedes Begriffs ist eben nur das Seyende, das Ens universale, was die alte scholastische Philosophie wohl eingesehen" (Ph. D. Mythologie, SW XII, 30). Zur Geschichte, SW X, 121: Hiezu gehört namentlich die Ueberzeugung, daß, was in uns erkennt, dasselbe ist mit dem, was erkannt wird.

[98] „Was man weist, muss man ganz und durchein wissen; es gibt kein halbes Wissen, oder vielmehr ein halbes Wissen ist gar kein Wissen“ (Abhandlungen zur Erläuterung des Idealismus der W.L., SW I, 461). Este supuesto, que exige no simplemente entender, sino comprenderlo todo, hace imposible una apertura no forzada a la realidad y a la revelación.

[99] De hecho, la exigencia de un saber absoluto, típica de sus primeros periodos, se transforma al final en la manifestación de un deseo de saber absoluto. He aquí un ejemplo: "Es wäre höchst erwünscht, wenn auch in der Folge der innern und äussern Schicksale der christlichen Kirche sich ein Gesetz entdecken liesse, und zwar womöglich ein dem allgemeinen, in allen geschichtlichen Entwicklungen herrschenden Gesetz analoges" (Ph. d. Offenbarung, SW XIV, 297). Según este texto, sería altamente deseable que todo se comportara en todas partes de una misma y única manera, lo cual es un síntoma inequívoco del ideal de sistema absoluto, sólo que cambiada la exigencia de saber absoluto en mero deseo; pero, exigido o deseado, el saber absoluto sigue siendo en ambos casos la meta.

[100] No se olvide que, para Schelling, la revelación cristiana, al igual que la mitología, es sólo un tramo de un proceso real o independiente de la razón (Einleitung i.d.Ph. D. Mythologie, SW XI, 247). Y ese proceso, en el que el hombre se halla envuelto, es el proceso teogónico (O.c., 243), cuyo tercer y más alto momento corresponde a la religión filosófica, que tiene como tarea histórica comprender tanto la mitología como la revelación (O.c., 250). Es cierto que él añade que esa religión no existe (Ibidem), pero, al decir que ella sería el producto final y la más alta expresión de la filosofía misma, quizás esté señalando al saber que corresponderá al eón futuro y cuya característica será la posesión de la ciencia suprema ( $P h$. d. Offenbarung, SW XIV, 328). Con todo, es a la filosofía, no al saber revelado, al que le corresponde y corresponderá la supremacía, pues la revelación es sólo un objeto, no una autoridad ni una fuente, para la filosofía $(P h$. d. Offenbarung, SW XIII, 133, 139 ss). 
afirmar que un Dios no sabido no es $\operatorname{Dios}^{101}$, o que la meta del saber humano es alcanzar el punto de vista de Dios ${ }^{102}$.

De modo semejante a lo que le sucedió con la publicación de sus Die Weltalter $^{103}$, quizás el no haber podido llevar a cabo una satisfactoria conjunción de sus nociones capitales -a consecuencia de la radical incompatibilidad entre lo que deseaba su voluntad y sus orientaciones básicas- haya sido lo que le retrajera de publicar por escrito, durante el resto de su vida, todo este complejo y forzado pensamiento, al que, sin embargo, no faltan destellos luminosos dispersos.

\section{REFERENCIAS}

Aristóteles: Physica, Aristotelis opera: Aristoteles Graece ex recognitione Immanuelis Bekkeri, edidit Academia Regia Borusica, 1831, tomus I, 184a-248b. - Perì psichés, Aristotelis opera: Aristoteles Graece ex recognitione Immanuelis Bekkeri, edidit Academia Regia Borusica, 1831, tomus I, $420 \mathrm{a}-435 \mathrm{~b}$. -Metaphysica, Aristotelis opera: Aristoteles Graece ex recognitione Immanuelis Bekkeri, edidit Academia Regia Borusica, 1831, tomus II, 980 a 1093b.

EsPInosa, Benito: Ethica more geometrico demonstrata, Spinoza Opera, in Auftrag

[101] „Der wahre Gott, der Gott als solcher, kann nur im Wissen seyn, und im völligen Gegensatz mit einem bekannten wenig überlegten Wort, aber in Uebereinstimmung mit den Worten Christi müssen wir sagen: der Gott, der nicht gewusst würde, wäre kein Gott“ (Einleitung i.D. Ph. . D. Mythologie, SW XI, 176.

[102] „Die Frage ist: wie die Handlung vom Standpunkt Gottes anzusehen. Dieß zu sagen, müßte uns Gott Standpunkt, d.h. Princip, geworden seyn; aber in dieser Wissenschaft ist er uns nur Ende... / ... Nicht auszuschließen endlich ist die, wenn auch noch so ferne Möglichkeit, daß das Ich, wodurch immer, dahin gebracht wird, sich selbst wieder zur Potenz, zum Nichtprincip $\mathrm{zu}$ machen, sich also $\mathrm{A}^{\circ}$ unterzuordnen und dieses als Princip wieder einzusetzen, womit, wie Sie sehen, erreicht wäre, was die Aufgabe dieser Wissenschaft ist, das Princip frei vom Seyenden und über Alles siegreich, kurz als Princip zu haben“"(Einleitung i. D. Ph. D. Mythologie, SW XI, 488-489). Huelga decir que Dios no tiene puntos de vista, sino omnisciencia, lo que nunca es ni será alcanzable por el hombre.

[103] „Wenn ich übrigens bisher gezögert und mich selbst nicht überwinden können auch nur die lezte Hand anzulegen, so war es hauptsächlich, weil ich noch immer fühlte, das Ganze nicht so ganz und völlig nach meinem Sinn ausführen zu können, als ich wollte. Wenn ich von dieser eigensinnigen Forderung abgieng, konnte ich das Werk längst in die Welt schicken. Aber es war doch billig, einmal auch bloss auf die eigne Genugthuung zu sehen, und was kann man am Ende für ein höheres Glück begehren, als nur sich ganz auszusprechen? Niemann geht so rein durch seine Zeit, das sich ihm nicht Vieles anhängt, was seinem eigentlichen Wesen gar nicht angehört. Diese Schlacken wegzuläutern, sich vom allem Fremden, Hemmenden loszumachen, und so in völligen Freiheit zu setzen, ist eigentlich das Schwere..." (Schelling an Atterbom, 29/01/1819, en Aus Schellings Leben. In Briefen, herausg. G.L. Plitt, Verlag von G. Hirzel, Leipzig, 1870, II, 429). 
der heidelberger Akademie der Wissenschaften, herausg. von C. Gebhardt, C. Winters Universitaetsbuchhandlung, Heidelberg, ${ }^{2}$ 1972, Band II, 43-308.

Falgueras, Ignacio: La 'res cogitans' en Espinosa, Eunsa, Pamplona, 1976.

- "Introducción general a las obras completas de Leonardo Polo", en Obras Completas de Leonardo Polo, Eunsa, Pamplona, 2015, v. I, 13-82.

-“Del círculo mágico a las edades del mundo. Un recorrido a través de las obras de Schelling", en Juan J. Padial, Alejandro Rojas (Hrsg.), Wahrheit und Freiheit in den philosophischen Systemen von Schelling und Hegel, Olms, Hildesheim, 2020.

Fichte, Johann Gottlieb, Über den Begriff der Wissenschaftslehre, en J.G. Fichtes Sämtliche Werke, herausg. von I.H. Fichte, Veit \& Comp. 1845/1846, Band I, 38-81.

Hegel, G. W. Friedrich: Fragment zur Philosophie des Geistes, en Berliner Schriften 1818-1831, G.W.F. Hegel Werke in zwanzig Bände, Suhrkamp Verlag, Freiburg a. M., Band 11, 517-550.

-Phänomenologie des Geistes, en G.W.F. Hegel Werke in zwanzig Bände, Suhrkamp Verlag, Freiburg a. M., 3. Band.

-Wissenschaft der Logik, en G.W.F. Hegel Werke in zwanzig Bände, Suhrkamp Verlag, Freiburg a. M., 5. und 6. Bände.

Kant, Inmanuel, Kritik der reinen Vernunft (2. Auflage), en Kants gesammelte Schriften, herausg. von der Königlich Preussischen Akademie der Wissenschaften, Band III.

Platón, Timeo, en Platonis Opera, John Burnet, E. typographeo Clarendoniano, 1900, IV, 17 a -92 c.

Plotino: Enéadas I-II, trad. J. Igal, Ed. Gredos, Madrid, 1982.

Polo, Leonardo: El Ser I: La existencia extramental, en Obras Completas de Leonardo Polo, Eunsa, Pamplona, 2015, v. III.

- Curso de Teoría del Conocimiento, tomo II, en Obras Completas de Leonardo Polo, Eunsa, Pamplona, 2016, v. V.

- Curso de Teoría del Conocimiento tomo IV, en Obras Completas de Leonardo Polo, Eunsa, Pamplona, 2019, v. VII.

- Antropología Trascendental, en Obras Completas de Leonardo Polo, Eunsa, Pamplona, 2016, v. XV.

-Nietzsche como pensador de dualidades, en Obras Completas de Leonardo Polo, Eunsa, Pamplona, 2018, v. XVII.

Schelling, F.W. JosePh: Sämtliche Werke, herausg. von K.F.A. Schelling, Cotta Verlag, Stuttgart, 1856-1861, 14 Bände.

-Aus Schellings Leben. In Briefen, herausg. von G. L. Plitt, Verlag von G. Hirzel, Leipzig, 1870, 3 Bände, reimpr. G. Olms Verlag, Hildesheim, 2003. 
-Die Weltalter. Fragmente, in den Urfassungen von 1811 und 1813, Schellings Werke, Münchner Jubiläumsdruck, Nachlassband, herausg. von M. Schröter, C.H. Beck'sche Verlagbuchhandlung, München, ${ }^{2} 1979$.

-Initia philosophiae universae. Erlanger Vorlesung WS 1820/21, herausg. von H. Fuhrmanns, H. Bouvier \& Co. Verlag, Bonn, 1969.

-Grundlegung der positiven Philosophie: Münchner Vorlesung WS 1832/33 und SS 1833, herausg. von H. Fuhrmans, Bottega d' Erasmo, Torino, 1972.

TomÁs DE AQuino: In quatuor Iibros Sententiarum, en S. Thomae Opera, curante R. Busa, Frommann-Holzboog, Stuttgart-Bad Cannstatt, 1980, vol. 1.

-Summa contra gentiles, en S. Thomae Opera, curante R. Busa, Frommann-Holzboog, Stuttgart-Bad Cannstatt, 1980, vol. 2.

-Summa Theologiae en S. Thomae Opera, curante R. Busa, Frommann-Holzboog, Stuttgart-Bad Cannstatt, 1980, vol. 2. 
